pected with greater certainty to return in full splendour in the present year, and the next, when observers will probably be repaid by watching for its appearance from midnight until daybreak on the morning of the second Monday in November, and again on the morning of the 13th of November, 1866.

\title{
A BRIEF HISTORY OF A MARINE TANK.
}

\section{BY SHIRLEY HIBBERD.}

IN the "Bricf History of a River Tank," published in February last (Intellectual Observer, vii., p. 38), I stated, as explicitly as I could, the principal features and advantages of the natural system of tank management, in order to present an illustration in the case of a tank so managed, and which was then, and still is, in the most perfect condition, and a familiar olject with a large circle of friends. In my sanctum. I have a marime tank which is fitted and managed on the same plan, and I propose to offer a few observations on this and some other vessels which have been used for marine collections.

When engaged in the experiments which were the foundation of my first written essays on the aquarium twelve year's ago, and subsequently of the Book of the Aquarium, and some scattered papers in periodicals, the grand difficulty was to determino an exact and self-sustaining balance between the various forces and influences that an aquarium brings into play. Every failure then occurring was the result of attempting too much, and of absolutely doing too much; and looking: back through all the experiences since acquired, I can say without a blush that the original notions entertained by aquarium practitioners were supremely ridiculous. Shall I ever forget the waste of precious time, and strength, and money in attempts to domesticate the larger forms of marine alga? Shall I ever forget the sanguine wishes that were entertained of the successful cultivation of Padina pavonia, Laminaric phyllitidis, Delesseria sanguinea, Ptilota phtumosa, and the lovely Griffithsia setacea, and how those hopes only faded out when years of watchfulness and wasted energy made it but too evident that it was easier to dream than to do? No, I shall never forget that the one great lesson that had to be learnt, and which needs to be repeated here, is that small quantities of sea water enclosed in vessels in dwelling-houses, are too peculiarly circumstanced to be made representative of Neptune's watery 
kingdom, but they may be made representative of rockpools and recesses. We may treat them as spoonfuls of water, and achieve such success as spoonfuls admit of; but we must not suppose we have the sea at our command, and a choice for our amusement of all its vegetable and animal denizens. Yet, strange to say, all the early experiments proceeded on the assumption that a tank is a miniature ocean. Now the ocean somewhere is deep, and so, accordingly, the tanks were at first made deep, and that was the greatest of all the blunders that then abounded in the incipient realm of aquarian practice. After hecatombs of victims had been offered up, it was found that shallow tanks answered better than deep ones. I had the good fortune to call attention to the importance of shallow tanks and subdued daylight in the Book of the Aquarium, in time to contribute to that consolidation of aquarian principles which has resulted in the establishment of extensive tidal aquaria at the gardens of the Zoological Society of Isondon, the Société d'Acclimatization at Paris, and the still more important and successful Aquaria at Berlin. It cannot be profitless to note the several points that have been successively demonstrated and established, because many persons are commencing the study of marine zoology, and need a little help from those who have had experience, and because, also, many who have had aquaria in their keeping for a series of years have not yet fully availed themselves of all the knowledge that has been accumulated on the subject.

Deep tanks are deep delusions. If it were possible to be content with a mere film of water over the animals they would, as a rule, prosper better than in depth enough to be completely submerged. The grand object is to present to the influence of the atmospherc the greatest possible extent of surface, and in shallow tanks this is of course accomplished. The slope-back tank is a heary and rather cumbrous vehicle, and FOR THAT REASON it surpasses every other form where it is not possible to establish a tidal arrangement. The great mass of slate is not quickly influenced by changes of temperature, and the slope affords a great extent of rocky bottom for a picturesque disposition of the interior, and for the full growth of oxygen-making vegetation. This form also allows of the transmission of light in a subrlued form, and an excess of light is impossible. Lastly, if the creatures confined in the vessel are of a roving habit, this propensity is encouraged, and wherever they roam they still remain visible.

Setting aside the notion of forming a complete submarine garden and zoological collection, let us consider the case somewhat in detail. The tank contains but a small bulk of water, 
and this cannot easily be renewed in the event of its becoming foul. The largest tank ever made, and the largest series of tanks ever made, are but as drops as compared with the ocean, and the physiological and chemical phenomena taking place within them are on the same small scale as the tanks themselves. For instance, in place of the rush of the tide with its crest of foam and grinding of pebbles in a rock-pool, giving life and energy and abundance of food to the creatures that the pool shelters, in the tank there is of necessity a deathlike stillness. This stillness reduces the capacity of the water for sustaining animal life, it is antagonistic to the generation of oxygen within or its absorption from the atmosphere. The algæ that grow in rock clefts and among littoral deposits are fully exposed to solar light, and are sometimes laid bare for hours to a burning sun. I know of many lovely meadows of Ulva and Enteromorpha, but principally the former, which are daily almost as dry at low tide as the hot sands above the water-line. We dare not imitate this feature in tank management. Sunshine makes our small pools opaque and viscid with an extravagant growth of superfluous vegctation, and as to laying the shoal dry daily it is out of the question, except it may for some unhappy individual who has nothing else to do than to pump or dip, and sell himself soul and body to a boxful of worms and periwinkles. If we keep marine animals at all, it must be by simpler methods than these. Lastly, to avoid tediousness, the animals we imprison are imprisoned; in other words, they do not select the site for themselves as when free, and with the immeasurable floor of the ocean for their playground; nor once consigned to the slate prison can they shift their quarters, even if, as may be the case, those quarter's are not exactly to their liking. Secing that in this brief view of a few of the details of the case, there are many difficulties to be encountered, it is a matter for gratulation and perhaps for pride, that so much has been done to enlarge the boundaries of our knowledge of the life that abounds in the deep sea.

Having fitted up and tended tanks innumerable, I always found that the best "weeds" for ordinary purposes were Ulva latissima and Enteromorpla compressa. I have made some practical notes on other forms of algre in the Book of the Aquarium, and have no intention now to repeat myself. I found, moreover, that the best of all materials for rockwork was mica-schist, because on this there soon occurred a spontaneous growth of microscopic algre and conferve, which is the best growth for a free generation of oxygen, and for keeping the tank in good condition. But with the best arrangements there was a certain amount of management wanted, and the object of fitting up the tank, of which a 
description follows, was to endeavour to discover a way of making a marine tank take care of itself, and which must of course wholly depend upon the arrangements made in the first instance.

On the 24th of June, 1862, I fitted up a Warrington slopeback tank in my study. It was placed with its back to the window and at about fifteen inches from the glass, so as to receive but a moderate amount of daylight, and that wholly throngh the glass cover; light from the front being impossible. The tank is made wholly of slate, except the front, which is plate glass, and the back is placed at an angle of 40 , which leaves a hollow cavity at the back; there is therefore no water chamber. The capacity of the tank is twenty gallons. Previous to fitting this tank I had by me a considerable quantity of débris from former experiments, and I set out in the fall sun a large collection of old shells of oysters, whelks, serpulæ, and other odd gatherings that had lost their interest because their inmates had perished. Conspicuous amongst these were some pieces of tile and rock thickly coated with acorn barnacles. Fearing there might be some gelatinous matter, the result of deposition when the animals perished, I placed them in a vessel of water for a few days to dissolve out any organic detritus, and then placed them in the sun to be thoroughly sweetened. These several materials were used for covering the sloping slate back of the tank, and their adoption was a most decided gain; in fact, they soon told me that heavy blocks of mica-schist or any other rock were wholly unnecessary. These slate tanks are very lieavy, and it is not desirable, unless a house is built expressly to receive them, to increase the weight by piling up rockwork inside them. In my cuse any serious addition to the combined weight of tank and water might cause the whole affair to subside from the study at the top of the house to the bed-room immediately below it, which would be an unpleasant circumstance, especially if it happened at night. But the bank of rocks at the back of the tank may be said to weigh nothing at all, consisting as it does wholly of old shells, and some of them very large, handsome, finely perforated and richly clothed shells of oysters from which the inmates departed many a year before. I found the shells. weather-beaten on the bench. Please make a note of this therefore, and if you are fitting up an aquarium, secure for it a few hampers of sea-side findings of an ancient shelly kind, and let the chief bulk consist of the largest and most ancient of the beach-strewn oyster shells that can be obtained. They are worth all the cost of carriage and more to an enthusiast in those matters, as will be seen presently.

The tank was fitted with these substitutes for rock, and 
filled with sea-water. I put in about half-a-dozen tufts of Ulva and Enteromorpha, and after four days had elapsed I stocked it with animal life as follows:- Six Actinia mesembryanthemum, two Sagartia viduate (anguicoma), four Sagartia bellis, four Bunoctes gemmacea, two Sagartia dianthus, one fine block of Corynactis viridis, and twelve periwinkles. I left all alone for a week, and at the end of that period most of the zoophytes had shrunk up, refusing any longer to display their gorgeous lays of flowery tentacles, and a black spot in one corner told of a death that had occurred. I soon found that the defunct party was a periwinkle, and he was removed. Three or four days afterwards a slimy appearance and a slight cloud indicated another death, and this time it was one of the Bunodes gemmacea. The next day I lost a mesembryanthemum.

When the last corpse was removed, a cloud rose from the spot where it had lain-the thermometer in the room being then at $83^{\circ}$, and the water was in a bad state. I was compelled, therefore, to remove the animals to a shallow pan, and leave them uncovered for a time, while I filtered enough water through charcoal to enable me to cover them with a thin film. The remainder of the water was exposed in a vessel to the sunshine for three days, and the empty tank was well cleansed and dried, and the shells exposed to sunshine to effect a perfect purification. While in the shallow pan I lost my block of Corynactis-every one perished. The tank was refitted, but the water was by no means so bright as when it was dipped from the salt sea. I made good what had been lost by evaporation by adding fresh water till the specific gravity bulb showed an inclination to sink. The same day a fine dianthus floated about instead of adhering; all the rest adhered well, and there was a fine display of tentacles, as is commonly the case after the animals have been disturbed. I removed the dianthus, and gave him a vessel to himself; but he never took hold, and died without a murmur. In the course of the summer I lost two more periwinkles; but though they lay some time decomposing before I knew it, I did not disturb the water, being content to remove them quietly, and leave the water and its inmates to fight it out.

From the time of first fitting the tank to last Midsummerday was a period of three years. On that day, considering the experiment satisfactory and sufficiently lengthened out, I distributed the little collection. At the time of distribution the stock consisted of five A. mesembryanthemum, two S. viduata, one S. dianthus, four S. bellis, four B. gemmacea, and eight periwinkles. The state of the tank was also very different to what it was for some months after the first furnishing. 
During the first winter all the tufts of Ulva and Enteromorpha perished. I thought then, and I still think, that in winter such a tank ought to be turned round to face the light, and be turned back to its former position some time at the end of February or the beginning of March. I wish I had done so, it would have made the experiment more complete probably. However, I did not; the fact is, such things are not easily moved, and so, if it occurs to one's mind to move them, the intention is scarcely likely to be carried into effect. Before the first winter set in, there was a perceptible green growth on some of the shells and stones, but not till the summer of 1863 was the growth of vegetation at all general. Then I became aware of the immense value of the old shells; for the old, rough, much pierced, and sponge-covered oyster shells acquired a rich deep green hue, and equally well clothed were the shells of the barnacles. On these latter, indeed, vegetation first appeared, and they are, no doubt, invaluable if well cleansed of animal matter before being inserted. But from first to last there has never occurred a single instance of "pea-soupiness," no ropy confervæ have been produced. The vegetation amounts to no more than a velvet-like, deep green coating on shells and stones, and this is richest on barnacles and oyster shells.

In every case of death subsequent to those particularized above, I have allowed the water to right itself, which it does in the course of a few days, or a week, the cloud spreading at first all over the tank, and then contracting to a black spot, which marks where the animal perished, and in the course of a fortnight (or less) this entirely disappears. It is an important fact that when the animals become seasoned, and the whole affair is left alone, one death does not necessarilylead to another, as in a tank heavily stocked, and exposed to a strong light; but as soon as the cloud caused by decomposition begins to spread, all the creatures close their disks, the mollusks contract and draw down their operculi, and in this state of torpor they all remain till things improve, when they again resume their activities. The most frequent cause of impurity is the result of feeding; for scraps of oyster or mussel given them are sometimes immediately ejected, and fall among the shells, and remain hidden, to cause putrefaction. The only means of preventing this is to remove every particle of food not receired by the animals; to feed seldom, so as to increase the probability that food will be welcome; and, lastly, to feed only on bright mornings, when the water is nearly transparent. Once a fortnight is often enougli to feed all the summer, and once in five or six weeks during winter.

During the first fow months after the tank was fitted, it 
had much attention, and was kept to a regular standard of density. By degrees I slackened in my attentions, and this did not result in disaster. Once, during the summer of 1863 , after long absence from home, and much absolute neglect of the tank, I observed that the water had sunk to a low level, and I inserted a hydrometer. What was my horror to find it register a specific gravity of 1,416 ! Yet even then the mesembryanthemums appeared as lively as usual, and dianthus was slowly imbibing and contracting, puffing itself out to enormous dimensions, and then becoming constricted, as if tied with a cord, as is the wont of this lovely conjuror of the deep. I found after a time that instead of adding fresh water by slow degrees, as I did at first, I might add sufficicnt at once to reduce the specific gravity to 1,028 without any harm to the inmates. They would, perhaps, close for a fow minutes, and then shine out with greater splendour than before. In every case when the water acquired an unnatural degree of density, the periwinkles attached themselves firmly, shrunk down deep into their shells, and drew their shutters down as tight as possible, and so remained till things came right again, when they would make up for lost time by increased activity and voracity. Since then the tank has frequently lost as much as two inches depth of watcr by evaporation, and I once found the specific gravity to be 1,529 ! Yet nothing worse happened than a general torpor and constriction, and a few hours after the reduction of the density to a proper standard, the creatures were all as lively as ever.

I have referred to cloudiness caused by deaths, but it is right Ishould say, thatwith the exception of those fer occurrences, the tank has always been delightfullybright, and there neveroccurred any growth on the front glass. When unstocked on the 24:th of June last, the watcr had the same bright appearance as when it was first dipped in the English Channel; but there were floating on the surface some small patches of brown flocculent matter, a sort of scum which I thought resulted from a gradual accumulation of a linty sort of dust, the result of the tank being amongst books, and which had crept in by the small slit of the sixtecnth of an inch which intervenes between the edge of the glass cover and the side of the tank at each end. 'The water was always rich in microscopic life, and its capacity for sustaining a mixed collection of marine animals appears to be in the proportion of not more than one to a gallon. For so large a creature as a dianthus I should think twe gallons none too much, with a shallow vessel, and vegetation produced in situ as essential elements of success; whereas with similar advantages two mesembryanthemums or daisies might be kept in a gallon of water. Even a periwinkle needs nearly a gallon 
of water, spread out over a considerable surface, to keep it alive two or three years. But by adopting this liberal rule; we make an end of the necessity for ærating, and for frequently renewing the stock of plants and animals.

\section{PLEASANT WAYS IN SCIENCE.}

\section{No. I.-Curiosities of Motion.}

UNDEn this title we propose from time to time to consider divers scientific questions in an informal manner, seizing rather upon their amusing, pictorial, or ideal aspects than attempting to build them up into the technical form of a methodical treatise. On object is to bring interesting results within the reach of those who may not have time or opportunity for arriving at them through a regular course of study, and to render assistance to those who diligently collect facts, but require help in the art of associating them together, so as to form a philosophy. We shall begin with some entertaining facts concerning Motion.

Of all earth's millions of human inhabitants how few know when they awake in the morning what enormous journeys they must take before the day will be over, and the dawn of the morrow will grreet their eyes. It would alarm a Londoner to tell him at daybreak that he should be shot off to Persia with the speed of a rifle bullet; and indeed we know no artificial mode of spinning him onward at anything like such a rate, even for short distances, with due regard to the continuance of his life. Nature, however, rolls him along with tremendous speed as the earth careers from west to east. In the course of twenty-three hours fifty-six minutes, four seconds, and nine hundredths of a second, the earth turns round on its imaginary axis. If at any moment we thought ourselves upright, we must remember that since that moment flitted away, we have been turned topsy-turry, and brought right again exactly in that space of time. How do we know this? It is one of the many things which the stars tell those who worship them with the homage which science pays to their brilliant and yet unseen orbs.* If we set up a tall convenient mark, or take a distant church spire, a lightning rod or a flag-staff, and note when any particular star is exactly over it, in precisely the time we have given, that star will be again in its place; and as

* The reader may consider as part of this series the paper, "We never See the Stars," which see to explain the paradox in the text. (See Vol.v., p. 47.) 